Canadian

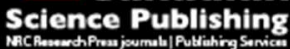

\title{
Canadian Journal of Zoology
}

Revue canadienne de zoologie

\section{Habitat use of coexisting Microtus vole species under competition and predation risk}

\begin{tabular}{|r|l|}
\hline Journal: & Canadian Journal of Zoology \\
\hline Manuscript ID & cjz-2016-0272.R2 \\
\hline Danuscript Type: & Article \\
\hline Complete List of Authors: & $\begin{array}{l}\text { Koivisto, E.; Turun Yliopisto, Biology } \\
\text { Hoset, Katrine; Turun Yliopisto, Biology } \\
\text { Huitu, Otso; Turun Yliopisto, Biology; Luonnonvarakeskus } \\
\text { Korpimäki, Erkki; Turun Yliopisto, Biology }\end{array}$ \\
\hline Keyword: & $\begin{array}{l}\text { RODENTS;SHREWS < Taxon, BEHAVIOUR < Discipline, COMPETITION < } \\
\text { Discipline, PREDATION < Discipline, SYMPATRY < Discipline, Microtus } \\
\text { agrestis, Microtus levis }\end{array}$ \\
\hline &
\end{tabular}

SCHOLARONE $^{\text {"x }}$

Manuscripts 


\section{Habitat use of coexisting Microtus vole species under competition}

\section{2 and predation risk}

3 Koivisto, E..$^{*}$, Hoset, K.S. ${ }^{2}$, Huitu, $\mathbf{O}^{3+}$ and Korpimäki, $\mathbf{E}^{4}$.

$5{ }^{1}$ Section of Ecology, Department of Biology, University of Turku, FI-20014 Turku, Finland,

6 elanko@utu.fi

$7{ }^{2}$ Section of Ecology, Department of Biology, University of Turku, FI-20014 Turku, Finland,

8 kathos@utu.fi

$9{ }^{3}$ Section of Ecology, Department of Biology, University of Turku, FI-20014 Turku, Finland

$10{ }^{+}$Current address: Natural Resources Institute Finland, FI-33720 Tampere, Finland,

11 otso.huitu@luke.fi

$12{ }^{4}$ Section of Ecology, Department of Biology, University of Turku, FI-20014 Turku, Finland,

13 ekorpi@utu.fi

14

15 * Corresponding author: Elina Koivisto, Tel: +358-41-4492300, fax: +358-2-333 6598,

16 email: elanko@utu.fi

21 Koivisto, E., Hoset, K.S., Huitu, O., and Korpimäki, E. Habitat use of coexisting Microtus

22 vole species under competition and predation risk 


\section{Abstract}

24 Competing species and predators can alter the habitat use of animals but both factors are 25 rarely simultaneously controlled for. We studied in experimental enclosures how closely 26 related species, the sibling vole (Microtus levis Miller, 1908) and the field vole (M. agrestis

27 L., 1761), adjust their habitat use when facing either the competing species or simultaneously 28 competition and predation risk. The species responded differently in their proportional use of 29 two habitat types, a low cover (productive but riskier) and a high cover (safer but poorer).

30 When alone, field voles used the low cover habitat according to availability at low densities,

31 but decreased its use with increasing density. Sibling voles, however, avoided the low cover 32 habitat in single-species populations. Under interspecific competition, the habitat use patterns 33 switched between species: sibling voles used the low cover habitat according to availability, 34 with decreasing use as densities increased. Sibling voles responded to predation risk by 35 showing a stronger density-dependent decrease in the use of low cover habitat. Field voles, 36 initially using mostly high cover, did not change behaviour under risk of predation. Our 37 results highlight the importance of considering both predation risk and interspecific 38 competition when interpreting patterns of habitat selection among coexisting species. 
39 Keywords: coexistence, density-dependent habitat use, field vole, Microtus agrestis, Microtus

40 levis, sibling vole

41 


\section{Introduction}

43 Competition for resources is one of the ecological factors known to have a strong impact on

44 animal communities (e.g. Hairston et al. 1960; Gurevitch et al. 1992) and may refer both to

45 the exploitative use of resources (exploitation competition, Schoener 1983) and to direct

46 antagonistic actions towards other individuals to monopolize a contested resource

47 (interference competition, Case and Gilpin 1974). Both types of competition can occur within

48 (intraspecific) and between species (interspecific). On an evolutionary time scale,

49 interspecific competition often results in resource partitioning (Schoener 1974; Pacala and

50 Roughgarden 1982; Roughgarden 1976; Abrams 1980; Luiselli 2006; Wauters et al. 2002).

51 As ecological consequences of competition, animals can for example modify their spatial or

52 temporal use of food, shelter or habitat (Koplin and Hoffmann 1968; Johannesen and

53 Mauritzen 1999; Ziv and Kotler 2003). Common responses are for example habitat shifts

54 (Koplin and Hoffmann 1968; Ziv et al. 1993) and niche contractions (Eccard and Ylönen 55 2002).

56 The outcome of competitive interactions between species can depend on habitat type and 57 differences in relative competitive strength of species between habitats (Morris and Grant 58 1972), and initial relative population density of competing species (Abramsky et al. 1990). 59 Consequently, competitive interactions and the densities of competing species may have 60 profound implications for habitat selection. Density-dependent habitat selection based on 61 ideal-free distribution (Fretwell and Lucas 1970) assumes that individuals select habitats to 62 maximize their fitness so that the relative use of the higher quality habitat declines as 63 population density increases, accompanied by an increased use of the lower quality habitat. In 
64 territorial animals, or interactions between species with different competitive strength, 65 density-dependent habitat selection may follow an ideal-despotic distribution (Fretwell and 66 Lucas 1970) where subordinates will be outcompeted from higher quality habitats, leading to 67 an increase in the use of lower quality habitats. Therefore, when two species prefer the same 68 high-quality habitat (at low densities), increasing total density may force the less competitive 69 species to increase its use of a low-quality habitat.

70 Predation can alter interspecific competitive interactions substantially (for reviews see Sih 71 et al. 1985; Gurevitch et al. 2000; Chase et al. 2002). In fact, predation may even override the 72 effects of interspecific competition altogether or change the outcome of competition (Persson 73 1991; Abramsky et al. 1998; Lin and Batzli 2001; Jermacz et al. 2015). As examples, 74 generalist predators may promote the coexistence of competing species through prey 75 switching, a process in which predators reduce densities of a given prey species as soon as 76 they begin to outnumber those of their competitors (Chase et al. 2002). Predators specialized 77 on a dominant competitor may initially promote coexistence by alleviating interspecific 78 competition. While the most conspicuous effect of predation is the removal of individuals, 79 predators can also have non-consumptive effects on their prey (Preisser et al. 2005). The 80 responses of prey to the presence of predators may include a decrease in feeding activity or 81 reduction in movements (Abramsky et al. 1998; Norrdahl and Korpimäki 1998; Koivisto and 82 Pusenius 2003; Salo et al. 2008; Haapakoski et al. 2015), or movement to a safer habitat 83 (Kotler et al. 1991; Creel et al. 2005). Furthermore, when facing a variety of predators, prey 84 might experience a trade-off between relative safety from one predator type and increased 85 vulnerability to another. For example, avoidance of avian predators that favour open areas for 86 hunting may predispose voles to small mustelids, like least weasels (Mustela nivalis L., 1766), 
87 which prefer hunting in cover (Korpimäki and Norrdahl 1989; Brandt and Lambin 2007). The

88 presence of a competing species can indirectly increase predation risk by attracting more

89 predators (apparent competition, Holt 1977), or lead to predator satiation if the total density of

90 competitors is sufficiently high (Hastings and Powell 1991).

91 Interspecific competition in rodents is well studied (for reviews see Grant 1972; Eccard

92 and Ylönen 2003). However, the majority of these studies have not controlled for predation

93 (but see e.g. Hughes et al. 1994; Schofield 2003; Jermacz et al. 2015). Here we evaluate the

94 effects of interspecific competition and population density on habitat use of two coexisting

95 small mammal species, the sibling vole (Microtus levis Miller, 1908) and the field vole (M.

96 agrestis L., 1761), and whether predation pressure changes their habitat use under

97 competition. The sibling vole and the field vole are the two most common vole species

98 inhabiting the grasslands of western Finland (Korpimäki and Norrdahl 1991). Both species are

99 folivorous, consume similar food resources, and coexist in seemingly similar habitats

100 (Myllymäki 1977) but sibling voles seem to be better adapted to cultivated fields than field

101 voles are (Myllymäki 1977; Norrdahl and Korpimäki 1993). Both species show synchronous

102 high-amplitude cyclic population oscillations with a cycle length of three years in our study

103 area (Huitu et al. 2004; Korpimäki et al. 2005). The sibling vole is slightly smaller and agile

104 than the field vole, it occurs in patches with relatively high densities (Norrdahl and Korpimäki

105 1993) and it appears to be a superior competitor over the field vole in the absence of predation

106 (Norrdahl and Korpimäki 1993; Koivisto et al. 2007). Despite this, the field vole is usually

107 more abundant in the wild than the sibling vole (Huitu et al. 2004). The mechanism allowing

108 the coexistence of these two species is not yet fully understood, but predation appears to play

109 an important role in the process (Norrdahl and Korpimäki 1993; Koivisto et al. 2008; Hoset et 
110 al. 2009). Coexistence of the two competitors could also reflect food differentiation not yet

111 identified.

112 We conducted an experiment in large outdoor predator-proof enclosures and fenced 113 control areas experiencing natural predation pressure. The grass of one third of each enclosure 114 and control area was cut and maintained short by mowing, thus creating a habitat with a high 115 risk of avian predation but constantly renewing food resources in the form of fresh grass. 116 Earlier studies have shown that the proportion of sibling voles compared to field voles was 117 smaller in hay fields with taller vegetation, but higher in intensively cultivated fields with 118 lower vegetation (Myllymäki 1977; Norrdahl and Korpimäki 1993). Despite being 119 competitively superior on a population level (Koivisto et al. 2007), sibling voles have smaller 120 body size than field voles and will thus most likely lose in one-on-one competition (Norrdahl 121 and Korpimäki 1993). Sibling voles are also more susceptible to predation than field voles 122 (Norrdahl and Korpimäki 1993; Koivisto et al. 2008), probably due to their tendency for 123 aggregation. Based on this information, and assuming that the low cover habitat has best 124 nutritional quality, we predicted that: 1) In the absence of predation and competition both 125 species will use the low cover habitat according to availability, but in a density-dependent 126 manner following ideal-free distribution, i.e., relative use of low cover habitat decreases with 127 increasing density. 2) Under competition, but in the absence of predation, sibling voles will 128 use the low cover habitat more than field voles, but 3) in the presence of predators, sibling 129 voles will respond more strongly to predation risk than field voles by shifting their habitat use 130 to high cover. 


\section{Study system}

134 The experiment was conducted in summer and autumn 2004 in Lapua, western Finland $\left(63^{\circ}\right.$

$\left.135 \mathrm{~N}, 23^{\circ} \mathrm{E}\right)$ at four separate study sites. The study sites were established in 1996 on old

136 farmland, are located $1.5-7 \mathrm{~km}$ apart and fall within an area of $12 \mathrm{~km}^{2}$. The sites are mostly

137 dominated by graminoids such as canary grass (Phalaris arundinacea L.), and herbs, e.g.,

138 nettle (Urtica dioica L), creeping thistle (Cirsium arvense L.) and fireweed (Epilobium

139 angustifolium L.). A more detailed description of the study sites and vegetation can be found

140 in Norrdahl et al. (2002). All applicable international, national, and institutional guidelines for

141 the care and use of animals were followed. All procedures involving animals were performed

142 in accordance with the ethical standards of the institution at which the studies were conducted

143 (see Acknowledgements for further details). The animals were cared for in accordance with

144 guidelines such as the Guide to the Care and Use of Experimental Animals. This research

145 adhered to the legal requirements of Finland and all institutional guidelines.

146 Each of the four sites contained two 0.5-hectare predator-proof enclosures, which were

147 constructed using hardware cloth (mesh size $12.7 \mathrm{~mm}$ ) extending $0.5 \mathrm{~m}$ below and $1.3 \mathrm{~m}$

148 above ground. A metal sheet $(40 \mathrm{~cm})$ was fastened to the upper edge of the fence to prevent

149 climbing by voles and mammalian predators. To prevent access by avian predators, the

150 enclosures were covered with nylon net (mesh size $10 \mathrm{~cm}$ ). In addition, three sites contained a

151 0.5-hectare control area each (hereafter control), which was surrounded by a low fence (40

$152 \mathrm{~cm}$ in height, $60 \mathrm{~cm}$ below ground). Each control area had six evenly distributed access points

153 where the top of the fence was lowered to a ca. $30 \mathrm{~cm}$ height to facilitate the entry of small

154 mustelids (least weasels and stoats Mustela erminea L., 1758). In fact, a few weasels were

155 caught in vole traps in the control areas during vole trapping and signs of mustelids (e.g. 
156 faeces) were detected also outside trapping periods. Thus, control fences enabled all predators

157 to enter and exit at will, while preventing the dispersal of voles. This set-up allowed us to 158 compare control populations with enclosed predator-free vole populations while avoiding 159 interpretation problems that could result from possible fence effects.

160 In each enclosure and control area, 48 traps (multiple capture Ugglan live-traps, Grahnab, 161 Sweden) were distributed evenly ca. $10 \mathrm{~m}$ apart. The traps were placed individually under 162 inverted plastic boxes $(40 \times 30 \times 25 \mathrm{~cm})$ that provided protection from weather. The grass of the 163 central $1 / 3$ strip of each area was kept short $(10-20 \mathrm{~cm})$ by mowing approximately every two 164 weeks throughout the summer (low cover habitat), and was thus short at the initiation of the 165 experiment. In the non-mowed sections, the natural vegetation reached a height of 100-200 $166 \mathrm{~cm}$ during the experiment (high cover habitat). Between the low and the high cover habitat 167 sections there was a $1.5 \mathrm{~m}$ wide zone which was treated with herbicide (RoundUp, Monsanto 168 Europe S.A., Belgium) to remove edge vegetation to measure the actual habitat selection 169 instead of occasional visits (Klemola et al. 2000). One-third (16) of the traps were distributed 170 in the low cover habitat and two-thirds (32) in the high cover habitat (Fig. 1).

172 Conduct of the experiment

173 Before the beginning of the experiment, we removed all rodents from the areas primarily by 174 live-trapping. In the enclosures also snap traps were used to remove the last few remaining 175 individuals not entering the live-traps as for the successful conduction of the experiment it 176 was essential that the enclosures were free of voles. Snap traps were placed under covers to 177 prevent birds from getting caught. Traps were checked at regular intervals and the trapped 178 voles were stored in a freezer for purposes of other studies. Voles used in the experiment were 
179 originally caught from the wild in Lapua and surroundings and kept in single-species 180 populations for a month in two 0.5 -ha predator-proof enclosures to reproduce. Individual 181 voles were allocated randomly to different treatments and areas for the experiment. Only 182 sexually mature individuals were used, as judged by a perforate vagina in females or scrotal 183 testes in males. In early July, we released four pairs (four females + four males) of field voles 184 or four pairs of sibling voles in the centre (short vegetation patch) of randomly selected 185 predator-proof enclosures [treatment: "no competition, no predation", (C-P-); $n=2$ enclosures 186 for each species, Fig. 1]. Two pairs each of both species were released in the centre of the 187 remaining enclosures ["competition, no predation", $(\mathrm{C}+\mathrm{P}-) ; n=4$ enclosures] and the centre 188 of fenced controls ["competition, predation", $(\mathrm{C}+\mathrm{P}+) ; n=3$ fenced controls]. Thus, all 189 replicates were founded with an equal density of 8 voles per enclosure (16 voles/ha). A 190 treatment "no competition, predation, $(\mathrm{C}-\mathrm{P}+)$ " is unfortunately missing from a full $2 \mathrm{x} 2$ design 191 due to logistic reasons, i.e. limited number of available study sites.

192 Population growth of voles was monitored by live-trapping on seven occasions from the 193 end of July to the beginning of November, using standard capture-mark-recapture techniques. 194 The time between trappings was ca. 2.5 weeks, being shortest at the beginning of the 195 experiment and longer towards the end of the experiment (range 2-4 weeks). Each trapping 196 period lasted six days. Two sites were trapped first for three days and then the other two sites 197 were trapped for the next three days. Traps were baited with Rat/Mouse Breeding Diet pellets 198 (Altromin GmbH, Germany) and checked three times per day, in the morning (at 6:00), in the 199 afternoon (14:00) and in the evening (21:00). Voles were marked individually, weighed, 200 sexed, and their current reproductive status noted. In all enclosures during the whole study 
201 period we caught altogether 11 bank voles (Myodes glareolus Schreber, 1780), one house 202 mouse (Mus musculus L., 1758) and 20 harvest mice (Micromys minutus Pallas, 1771) in 203 addition to the study species. Of these species, only bank voles are potential competitors for 204 the study species. Bank voles have a different diet than Microtus voles, but they can still 205 compete for space. Microtus voles are, however, competitively superior to bank voles 206 (Henttonen et al. 1977), so we did not expect bank vole presence in this low numbers to affect 207 the competitive outcome between the Microtus. However, all the other rodents than Microtus 208 voles were removed from the experimental enclosures when encountered to avoid any 209 potential interference in our results. They were taken out of the enclosure and released to a 210 suitable habitat in a nearby location.

\section{Statistical analyses}

213 Estimates of population density for voles were calculated from trapping data using the 214 jackknife estimator for model $M_{h}$ in the program CAPTURE (Otis et al. 1978) with separate 215 estimates for each species in all enclosures. Results of the ensuing differences in population 216 dynamics of the voles when protected from predation, with and without the competing species 217 present are reported in Koivisto et al. (2007).

218 As an individual habitat selection index, we calculated the proportion of captures for each 219 individual vole that occurred within the low cover habitat. Due to low population densities, 220 particularly in the beginning of the experiment, we pooled enclosure-specific data from the

221 first three trapping occasions into one period. Data for trapping occasions four and five, and 222 for six and seven, were similarly combined into two separate periods, thereby reducing the 223 number of trapping periods to three. Individuals appear in the data only once per period, but 
224 they may appear in more than one period across the whole dataset. Due to the unbalanced 225 study design (no treatment C-P+ due to constraints of study sites), the effects of competition 226 and predation were tested separately ( $\mathrm{C}+\mathrm{P}-$ vs. $\mathrm{C}-\mathrm{P}-$ and $\mathrm{C}+\mathrm{P}+$ vs. $\mathrm{C}+\mathrm{P}-$, respectively). This 227 separation allowed us to observe how competition affects habitat use of field voles and sibling 228 voles, and how predation moderates the habitat use under competition. However, we cannot 229 evaluate whether predation without competition would elicit similar responses as predation 230 with competition or not. All analyses were performed using R statistical software (Version 231 3.1.2, R Core Team 2014).

232 Effects of competition (1068 captures of 837 individuals from 8 populations) and 233 predation (634 captures of 505 individuals from 7 populations) were analysed separately by 234 fitting generalized linear mixed models using the function glmer in package lme4 (Bates et al. 235 2014) with individual habitat selection index as a response variable, assuming a binomial 236 response distribution because the index is based on proportions. We set enclosure identity as a 237 random intercept to control for the experimental design, but did not include individual ID as 238 only a small fraction of individuals (ca 20\%) were observed more than once. Treatment 239 (competition or predation), species, trapping period, the combined average density of both 240 vole species in each enclosure, and their two- and three-way interactions were evaluated as 241 explanatory variables. Combined density for both species was mean centred, i.e. the mean 242 value was subtracted from the mean, to facilitate model convergence and parameter 243 estimation, following suggestions by Gelman and Hill (2006). True densities ranged 2.7 24491.50 (sibling vole populations, C-), 10.0 - 93.0 (field vole populations, C-), 3.7 - 93.0 245 (combined populations without predation, $\mathrm{C}+\mathrm{P}-$ ) and $6.7-70.5$ (combined populations with 
246 predation, $\mathrm{C}+\mathrm{P}+$ ). We used the combined vole density as models fitted with combined density

247 had lower AICc-values than models fitted with intraspecific density and allowed more 248 flexibility in modelling. Estimates and figures indicate that combined vole density 249 approximated intraspecific density, and results are essentially the same regardless of which 250 density measure we use (see Supplementary material S1 for results using centred intraspecific 251 density).

252 We checked the models for (multi-) collinearity by calculating variance inflation factors 253 (VIF) for the models. VIF values above 10 indicate collinearity issues (Graham 2003). We 254 found that in both competition and predation models that simultaneously included trapping 255 period and rodent density as explanatory factors, routinely showed VIF values above 20 . The 256 high VIF values suggest high collinearity between the two factors as models run with only 257 density or period showed VIF values $<5$. Furthermore, density significantly increased with 258 successive trapping occasions (competition sub-data: $R_{\text {adj }}^{2}=0.14, F_{1,22}=4.845, P=0.039$; 259 predation sub-data: $R_{\text {adj }}^{2}=0.38, F_{1,19}=13.350, P=0.002$ ), and we have no reason to believe 260 that other factors mediated through trapping period would affect distribution between high 261 and low cover habitats differently. Therefore, we further report findings from models 262 (competition and predation) that include species, treatment and centred density with two- and 263 three-way interactions. Including trapping period in the models did not change the results 264 qualitatively, i.e. the response to density did not differ between trapping occasions.

265 Since changes in relative habitat use with increasing density may differ between age 266 groups, we also ran similar models as described above that included age (adult or juvenile) 267 and interactions with centred combined density, species and treatment. Although there were 268 significant effects of the interaction between age and treatment, the proportional use of the 
269 low cover habitat did not differ markedly between age groups. We therefore describe these

270 results in Supplementary material S2.

272 Results

273 The two vole species responded differently to the presence of interspecific competition in 274 their use of the low cover habitat as evident from significant interactions between treatment 275 and species $\left(\chi^{2}=23.6, P<0.001\right)$ and density and species $\left(\chi^{2}=4.8, P=0.029\right)$. The 276 interaction effect between density and species was further affected by treatment (three-way 277 interaction: $\chi^{2}=11.4, P<0.001$, results from the full model in Table 1). Sibling voles' use of 278 low cover habitat did not respond to vole density in single-species populations (C-P-) and was 279 consistently lower than expected based on availability (0.33, i.e. $1 / 3$ of the enclosure area). In 280 mixed-species populations $(\mathrm{C}+\mathrm{P}-)$, sibling voles used low cover habitat slightly below to 281 availability at low density and decreased use of this habitat (C+P-, Fig. 2) with increasing 282 density. Field voles used the low cover habitat according to availability at low density in 283 single-species populations, and decreased their use of low cover habitat with increasing 284 density (Fig. 2). In mixed-species populations, field voles used the low cover habitat less than 285 availability and the use did not respond to increasing density (Fig. 2).

286 The two species also differed in their responses to predation as seen from the significant 287 main effect of species $\left(\chi^{2}=20.8, P<0.001\right)$, two-way interaction between species and 288 density $\left(\chi^{2}=7.6, P=0.006\right)$, and three-way interaction between treatment, density and 289 species $\left(\chi^{2}=8.7, P=0.003\right.$, full results in Table 1$)$. Field voles did not respond to the 290 predation treatment $(\mathrm{C}+\mathrm{P}+)$ by changing their use of the low cover habitat (Fig. 3). Sibling 
291 voles used the low cover habitat as much in presence of predation as in the absence of 292 predation, but the use of low cover habitat by sibling voles decreased more strongly with 293 density in presence of predators than in the absence of predators (C+P-, Fig. 3).

\section{Discussion}

296 We found significant differences in habitat use between the two vole species in response to 297 sympatric interspecific competitors, population density and predation risk. When the species 298 occurred alone, without the influence of competition or predation risk, field voles used the 299 low cover habitat according to habitat availability $(0.33$, i.e. one third of the enclosure area) at 300 low population densities while showing a density-dependent decrease in proportion of use, 301 following so ideal-free distribution and supporting our first prediction. A potential 302 mechanistic explanation for this observed pattern is that field voles favour certain plants that 303 were more abundant in the mowed area when vole densities were low. As densities grew, the 304 preferred plants may have been eliminated (see Norrdahl et al. 2002), which could have led to 305 a decrease in the relative use of low cover habitat (Hansson 1995).

306 Conversely, in absence of interspecific competition sibling voles used the short grass 307 below to its availability, even at low densities without predation risk, thus contradicting our 308 first prediction in contrast to field voles. This pattern could be due to sibling voles being more 309 susceptible to predation than field voles (Norrdahl and Korpimäki 1993; Koivisto et al. 2008;

310 Hoset et al. 2009) and innately perceiving low cover habitat as too risky. Even though there 311 was no actual predation in the predator-proof enclosures, there can be occasional avian 312 predators, including Eurasian kestrels (Falco tinnunculus L., 1758), short-eared owls (Asio 
313 flammeus Pontoppidan, 1763) and long-eared owls (A. otus L., 1758) flying above the

314 enclosures, which may elicit anti-predatory behaviour (Gerkema and Verhulst 1990). Based

315 on the overall higher use of high cover habitat by voles, the main source of predation risk also

316 in the control areas with natural predation was more likely the presence of avian predators

317 than the presence of small mustelids hunting in the cover (see Haapakoski et al. 2015).

318 When exposed to interspecific competition but not to predation risk, field voles used the 319 low cover habitat less than in single-species populations, while sibling voles conversely used 320 the low cover habitat more in mixed-species populations than in singe-species populations.

321 We found thus support for the prediction that sibling voles use the low cover habitat more 322 than field voles under competition. In fact, sibling voles used low cover habitat close to its 323 availability at low densities and showed density-dependent response in the relative habitat 324 use. Field voles neither used low cover habitat under competition, nor showed any density325 dependent response in use. This is probably due to sibling voles being better adapted to low 326 vegetation cover habitats than field voles. Alternatively, sibling voles might have responded 327 differently to increasing population densities in the presence of field voles than when alone 328 due to their better tolerance towards higher densities of conspecific than interspecific 329 competitors, as sibling voles are known to form high-density patches (Norrdahl and 330 Korpimäki 1993).

331 Under coexistence in the absence of predation, the two species behaved as previously 332 reported (Myllymäki 1977; Norrdahl and Korpimäki 1993): sibling voles used the low cover 333 habitat proportionally more than field voles. The response of field voles to interspecific 334 competition by niche contraction has previously been documented in voles (e.g. Eccard and 335 Ylönen 2002). Field voles may opt for safer, high cover habitats because of the possibility that 
336 aggregations of sibling voles lure more predators to an area (apparent competition, Holt

337 1977). Alternatively, the observed pattern could also result from apparent predation, a process

338 in which subordinate animals increase their use of safe foraging patches, not as a response to

339 predation risk, but in response to the density increase of nearby dominant competitors (Morris

340 2009; Halliday and Morris 2013).

341 We found partial support for prediction three, that sibling voles respond more strongly to 342 predation than field voles. Sibling voles showed a steeper density-dependent reduction in their 343 use of low cover habitat when exposed to predation than in the absence of it. Overall, the 344 observed patterns were similar to what was observed in mixed-species populations in the 345 absence of predation. The observed reduction in the relative use of low cover habitat at high 346 density is in contrast to earlier accounts of sibling vole habitat preferences (Myllymäki 1977; 347 Norrdahl and Korpimäki 1993), but do follow the predictions of ideal-free distribution 348 between a preferred habitat and a less preferred habitat (Lucas and Fretwell 1970).

349 In this experiment, sibling voles in control areas may have either reacted to a perceived 350 risk of avian predation by shifting more to high cover or been selectively removed from the 351 population. Unfortunately, no data exist to verify which of these the most likely cause is.

352 Nonetheless, due to their tendency of forming high-density patches (Norrdahl and Korpimäki 353 1993), sibling voles have been suggested to be particularly vulnerable to patch-searching 354 avian predators (Korpimäki 1992; Koivunen et al. 1996). By contrast, field voles under 355 interspecific competition barely used the low cover habitat to begin with, so there was no 356 need for them to shift habitat in response to avian predation risk. While the use of high cover 357 might be effective against avian predators, it may predispose voles to small mustelids hunting 358 under cover (Korpimäki and Norrdahl 1989; Brandt and Lambin 2007). Data from the same 
359 enclosures show that weasels almost solely used the high cover habitat, while avian predators

360 preferred low cover (Koivisto et al. 2016). Voles appear either to consider avian predators a

361 bigger threat than mammalian predators or to have more evolved anti-predator strategies

362 against the former, and commonly respond more strongly to avian predation risk (Korpimäki

363 et al. 1996; see also Fey et al. 2006).

364 Based on the differences in responses found here, the coexistence of these two sympatric

365 small mammal species cannot be explained by temporally consistent differences in habitat

366 use. Coexistence may, however, be facilitated by divergent fitness benefits in different

367 habitats with and without competition, as has been suggested for habitat use of Microtus voles

368 compared to Myodes voles (Morris and Grant 1972). The use of low cover habitat observed in

369 sibling voles in the absence of predators in single-species populations without competition

370 and in mixed-species populations with competition suggests that sibling voles use more the

371 safe habitat when there are no competitors, but are prone to use the more risky habitat when

372 competitors are present, indicating that the fitness benefits of each habitat depend on the

373 presence or absence of competitors. Alternatively, other yet not identified mechanisms, such

374 as differences in vigilance between the species (Dupuch et al. 2013), could explain the

375 coexistence of these vole species under temporal dynamics of fear. Although sibling voles use

376 the low cover habitat according to availability at the lowest population densities also under

377 predation, at medium densities most individuals already use the less risky high cover habitat.

378 Without predation, a higher proportion of sibling voles would still use the low cover habitat at

379 similar medium densities. Our results thus highlight the importance of including effects of

380 both predation risk and competition when interpreting the patterns of habitat distribution 
381 observed in nature among coexisting species and not take them solely as a result of one or the

382 other (see also e.g. Morris 2009; Dupuch et al. 2014).

383

384

385 Acknowledgements

386 Pirjo Isotupa, Emmu Lahtinen, Teppo Puolakka and Rauno Varjonen are thanked for assisting

387 in field work and Mari S. Lyly for providing the animal drawings. Farmers Matti Antila and

388 Jaakko Yli-Härsilä kindly allowed maintaining fences on their property, and the Ikola family

389 offered accommodation and other facilities. Research was conducted under institutional

390 animal use permit no STO/1053(8.9.199), 1132/712-92, 1286/712-86 and project animals use

391 permit no 07-10 ESLH-2007-03499/Ym-23. This work was supported by the Academy of

392 Finland (grant numbers 8206140,8123379 to EKor and grant number 106036 to OH) and by

393 the Finnish Cultural Foundation and Finnish Cultural Foundation, South Ostrobothnia

394 Regional fund (personal grants to EKoi).

395

396 References

397 Abrams, P.A. 1980. Resource partitioning and interspecific competition in a tropical hermit

398 crab community. Oecologia, 46(3): 365-379. Available from

399 http://www.jstor.org/stable/4216182 [accessed 27 October 2016].

400 
401 Abramsky, Z., Rosenzweig, M.L., Pinshow, B., Brown, J.S., Kotler, B., and Mitchell, W.A.

402 1990. Habitat selection: an experimental field test with two gerbil species. Ecology, 71(6):

403 2358-2369. Available from http://www.jstor.org/stable/1938646 [accessed 27 October 2016].

404

405 Abramsky, Z., Rosenzweig, M.L., and Subach, A. 1998. Do gerbils care more about

406 competition or predation? Oikos, 83(1): 75-84. Available from

407 http://www.jstor.org/stable/3546548 [accessed 27 October 2016].

408

409 Bates, D., Maechler, M., Bolker, B., and Walker, S. 2014. _lme4: Linear mixed-effects

410 models using Eigen and S4_. R package version 1.1-7. Available from http://CRAN.R-

411 project.org/package=lme4 [accessed 27 October 2016].

412

413 Bengtsson, J. 1989. Interspecific competition increases local extinction rate in a

414 metapopulation system. Nature, 340: 713-715. doi:10.1038/340713a0.

415

416 Brandt, M.J., and Lambin, X. 2007. Movement patterns of a specialist predator, the weasel

417 Mustela nivalis exploiting asynchronous cyclic field vole populations. Acta Theriol. 52(1):

418 13-25. doi:10.1007/BF03194195.

419

420 Case, T.J., and Gilpin, M.E. 1974. Interference competition and niche theory. Proc. Natl.

421 Acad. Sci. U.S.A. 71(8): 3073-3077. Available from

422 http://www.pnas.org/content/71/8/3073.abstract [accessed 27 October 2016]. 
424 Chase, J.M., Abrams, P.A., Grover, J.P., Diehl, S., Chesson, P., Holt, R.D., Richards, S.A., 425 Nisbet, R.M., and Case, T.J. 2002. The interaction between predation and competition: a 426 review and synthesis. Ecol. Lett. 5(2): 302-315. doi:10.1046/j.1461-0248.2002.00315.x.

Creel, S., Winnie, J.Jr., Maxwell, B., Hamlin, K., and Creel, M. 2005. Elk alter habitat selection as an antipredator response to wolves. Ecology, 86(12): 3387-3397. doi:10.1890/050032.

Dupuch, A., Morris, D.W., and Halliday, W.D. 2013. Patch use and vigilance by sympatric 433 lemmings in predator and competitor-driven landscapes of fear. Behav. Ecol. Sociobiol. 434 68(2): 299-308. doi:10.1007/s00265-013-1645-z.

Dupuch, A., Morris, D.W., Ale, S.B., Wilson, D.J., and Moore, D.E. 2014. Landscapes of fear 437 or competition? Predation did not alter habitat choice by Arctic rodents. Oecologia, 174(2): 403-412. doi:10.1007/s00442-013-2792-7.

Eccard, J.A., and Ylönen, H. 2002. Direct interference or indirect exploitation? An

441 experimental study of fitness costs of interspecific competition in voles. Oikos, 99(3): 580-

442 590. Available from http://www.jstor.org/stable/3547846 [accessed 27 October 2016].

444 Eccard, J.A., and Ylönen, H. 2003. Interspecific competition in small rodents: from 445 populations to individuals. Evol. Ecol. 17(4): 423-440. doi:10.1023/A:1027305410005. 
447 Fey, K., Banks, P.B., and Korpimäki, E. 2006. Different microhabitat preferences of field and 448 bank voles under manipulated predation risk from an alien predator. Ann. Zool. Fenn. 43(1):

449 9-16. Available from http://www.jstor.org/stable/23735895 [accessed 27 October 2016].

451 Fretwell, S.D., and Lucas, H.L. 1970. On territorial behavior and other factors influencing 452 habitat distribution in birds. I. Theoretical development. Acta Biotheor. 19: 16-36.

454 Gelman, A., and Hill, J. 2006. Data Analysis Using Regression and Multilevel/Hierarchical 455 Models. Cambridge University Press, New York.

Gerkema, M.P., and Verhulst, S. 1990. Warning against unseen predator: a functional aspect 458 of synchronous feeding in the common vole, Microtus arvalis. Anim. Behav. 40(6): 1169459 1178. Available from http://dx.doi.org/10.1016/S0003-3472(05)80183-6 [accessed 27 460 October 2016].

462 Graham, M.H. 2003. Confronting multicollinearity in ecological multiple regression. Ecology, 463 84(11): 2809-2815. doi:10.1890/02-3114.

464

465 Grant, P.R. 1972. Interspecific competition among rodents. Annu. Rev. Ecol. Syst. 3: 79-106. 466 Available from http://www.jstor.org/stable/2096843 [accessed 27 October 2016]. 
468 Gurevitch, J., Morrow, L.L., Wallace, A., and Walsh, J.S. 1992. A meta-analysis of

469 competition in field experiments. Am. Nat. 140(4): 539-572. Available from

470 http://www.jstor.org/stable/2462913 [accessed 27 October 2016].

471

472 Gurevitch, J., Morrison, J.A., and Hedges, L.V. 2000. The interaction between competition 473 and predation: a meta-analysis of field experiments. Am. Nat. 155(4): 435-453.

474 doi:0.1086/303337.

475

476 Haapakoski, M., Sundell, J., and Ylönen, H. 2015. Conservation implications of change in 477 antipredator behavior in fragmented habitat: Boreal rodent, the bank vole, as an experimental 478 model. Biol. Conserv. 184: 11-17. Available from

479 http://dx.doi.org/10.1016/j.biocon.2014.12.023 [accessed 27 October 2016].

480

481 Hairston, N.G., Smith, F.E., and Slobodkin, L.B. 1960. Community structure, population 482 control, and competition. Am. Nat. 94: 421-425.

483

Halliday, W.D., and Morris, D.W. 2013. Safety from predators or competitors? Interference competition leads to apparent predation risk. J. Mammal. 94(6): 1380-1392. doi: Available from http://dx.doi.org/10.1644/12-MAMM-A-304.1 [accessed 27 October 2016].

488 Hansson, S. 1995. Effects of exploitative food competition on food niche dynamics - a 489 simulation analysis. Ecol. Model. 77(2-3): 167-187. doi:10.1016/0304-3800(93)E0075-E. 
491 Hastings, A., and Powell, T. 1991. Chaos in a three-species food chain. Ecology, 72(3): 896-

492 903. doi: 10.2307/1940591.

493

494 Henttonen, H., Kaikusalo, A., Tast, J., and Viitala , J. 1977. Interspecific Competition

495 between Small Rodents in Subarctic and Boreal Ecosystems. Oikos, 29(3): 581-590.

496 doi:10.2307/3543596.

497

498 Holt, R.D. 1977. Predation, apparent competition and the structure of prey communities.

499 Theor. Popul. Biol. 12(2): 197-229.

500

501 Hoset, K.S., Koivisto, E., Huitu, O., Ylönen, H., and Korpimäki, E. 2009. Multiple predators

502 induce risk reduction in reduction in coexisting vole species. Oikos, 118(9): 1421-1429.

503 doi:10.1111/j.1600-0706.2009.17263.x.

504

505 Hughes, J.J., Ward, D., and Perrin, M.R. 1994. Predation risk and competition affect habitat

506 selection and activity of Namib Desert gerbils. Ecology, 75(5): 1397-1405.

507 doi:10.2307/1937463.

508

509 Huitu, O., Norrdahl, K., and Korpimäki, E. 2004. Competition, predation and interspecific

510 synchrony in cyclic small mammals. Ecography, 27(2): 197-206. doi:10.1111/j.0906-

$511 \quad 7590.2003 .03684 . x$.

512 
513 Jermacz, J., Dzierżyńska, A., Kakareko, T., Poznańska, M., and Kobak, J. 2015. The art of

514 choice: predation risk changes interspecific competition between freshwater amphipods.

515 Behav. Ecol. 26(2): 656-664. doi:10.1093/beheco/arv009.

516

517 Johannesen, E., and Mauritzen, M. 1999. Habitat selection of grey-sided voles and bank voles

518 in two subalpine populations in southern Norway. Ann. Zool. Fenn. 36(4): 215-222.

519 Available from http://www.jstor.org/stable/23735729 [accessed 27 October 2016].

521 Klemola, T., Koivula, M., Korpimäki, E., and Norrdahl, K. 2000. Experimental tests of 522 predation and food hypotheses for population cycles of voles. Proc. R. Soc. Lond. B Biol. Sci. 523 267(1441): 351-356. doi:10.1098/rspb.2000.1008.

525 Koivisto, E., and Pusenius, J. 2003. Effects of temporal variation in the risk of predation by 526 least weasel (Mustela nivalis) on feeding behavior of field vole (Microtus agrestis). Evol. 527 Ecol. 17(5): 477-489. doi:10.1023/B:EVEC.0000005594.40721.17.

Koivisto, E., Huitu, O., and Korpimäki, E. 2007. Smaller Microtus vole species competitively 530 superior in the absence of predators. Oikos, 116(1): 156-162. doi:10.1111/j.2006.0030$531 \quad$ 1299.15254.x.

533 Koivisto, E., Huitu, O., Sundell J., and Korpimäki, E. 2008. Species-specific limitation of 534 vole population growth by least weasel predation: facilitation of coexistence? Oikos, 117(1): 535 6-12. doi:10.1111/j.2007.0030-1299.15938.x. 
537 Koivisto, E., Hoset, K.S., Le Tortorec, A.H., Norrdahl, K., and Korpimäki, E. 2016. Mobility

538 of a small mammalian predator changes according to the activity patterns of potential

539 intraguild predators. J. Zool. (Lond.) 298(2): 121-127. doi:10.1111/jzo.12293.

541 Koivunen, V., Korpimäki, E., Hakkarainen, H., and Norrdahl, K. 1996. Prey choice of

542 Tengmalm's owls (Aegolius funereus funereus): preference for substandard individuals? Can.

543 J. Zool. 74(5): 816-823. doi:10.1139/z96-094.

545 Koplin, J.R., and Hoffmann, R.S. 1968. Habitat overlap and competitive exclusion in voles

546 (Microtus). Am. Midl. Nat. 80(2): 494-507. doi:10.2307/2423541.

548 Korpimäki, E. 1992. Diet composition, prey choice and breeding success of Long-eared Owls:

549 effects of multiannual fluctuations in food abundance. Can. J. Zool. 70(2): 2373-2381.

550 doi:10.1139/z92-319.

551

552 Korpimäki, E., and Norrdahl, K. 1989. Avian predation on mustelids in Europe 1: occurrence

553 and effects on body size variation and life traits. Oikos, 55(2): 205-215.

554 doi:10.2307/3565424.

555

556 Korpimäki E., and Norrdahl, K. 1991. Do breeding nomadic avian predators dampen

557 population fluctuations of small mammals? Oikos, 62(2): 195-208. doi:10.2307/3545265. 
559 Korpimäki, E., Koivunen, V., and Hakkarainen, H. 1996. Microhabitat use and behavior of

560 voles under weasel and raptor predation risk: predator facilitation? Behav. Ecol. 7(1): 30-34.

561 doi:10.1093/beheco/7.1.30.

562

563 Korpimäki, E., Norrdahl, K., Huitu, O., and Klemola, T. 2005. Predator-induced synchrony in 564 population oscillations of coexisting small mammal species. Proc. R. Soc. Lond. B Biol. Sci. 565 272(1559): 193-202. doi:10.1098/rspb.2004.2860.

566

567 Kotler, B.P., Brown, J.S., and Hasson, O. 1991. Factors affecting gerbil foraging behavior and 568 rates of owl predation. Ecology, 72(6): 2249-2260. doi:10.2307/1941575.

569

570 Lin, Y.K., and Batzli, G.O. 2001. The effect of interspecific competition on habitat selection 571 by voles: an experimental approach. Can. J. Zool. 79(1): 110-120. doi:10.1139/z00-184. 572

573 Luiselli, L. 2006. Resource partitioning and interspecific competition in snakes: the search for 574 general geographical and guild patterns. Oikos, 114(2): 193-211. doi:10.1111/j.2006.0030575 1299.14064.x.

576

577 Morris, D.W. 2009. Apparent predation risk: tests of habitat selection theory reveal

578 unexpected effects of competition. Evol. Ecol. Res. 11: 209-225. 579

580 Morris, R.D., and Grant, P.R. 1972. Experimental studies of competitive interaction in a two581 species system. J. Anim. Ecol. 41(2): 275-290. doi:10.2307/3469. 
583 Myllymäki, A. 1977. Interactions between the field vole Microtus agrestis and its microtine 584 competitors in Central-Scandinavian populations. Oikos, 29(3): 570-580.

585 doi:0.2307/3543595.

587 Norrdahl, K., and Korpimäki, E. 1993. Predation and interspecific competition in two

588 Microtus species. Oikos, 67(1): 149-158. doi:10.2307/3545105.

590 Norrdahl, K., and Korpimäki, E. 1998. Does mobility or sex of voles affect risk of predation 591 by mammalian predators? Ecology, 79(1): 226-232. doi:10.2307/176877.

593 Norrdahl, K., Klemola, T., Korpimäki, E., and Koivula, M. 2002. Strong seasonality may 594 attenuate trophic cascades: vertebrate predator exclusion in boreal grassland. Oikos, 99(3): 595 419-430. doi:10.1034/j.1600-0706.2002.12025.x.

596

597 Otis, D.L., Burnham, K.P., White, G.C., and Anderson, D.R. 1978. Statistical inference from 598 capture data on closed animal populations. Wildl. Monogr. 62: 1-135.

599

600 Pacala, S., and Roughgarden, J. 1982. Resource partitioning and interspecific competition in 601 two two-species insular Anolis lizard communities. Science, 217(4558): 444-446.

602 doi:10.1126/science.217.4558.444.

603 
604 Persson, L. 1991. Behavioral response to predators reverses the outcome of competition

605 between prey species. Behav. Ecol. Sociobiol. 28(2): 101-105. Available from

606 http://www.jstor.org/stable/4600523 [accessed 27 October 2016].

607

608 Preisser, E.L., Bolnick, D.I., and Benard, M.F. 2005. Scared to death? The effects of

609 intimidation and consumption in predator-prey interactions. Ecology, 86(2): 501-509.

610 doi:10.1890/04-0719.

611

612 Pusenius, J., and Schmidt, K.A. 2002. The effects of habitat manipulation on population

613 distribution and foraging behavior in meadow voles. Oikos, 98(2): 251-262.

614 doi:0.1034/j.1600-0706.2002.980207.x.

615

616 R Core Team 2014. R: A language and environment for statistical computing. R Foundation

617 for Statistical Computing, Vienna, Austria. Available from http://www.R-project.org/

$618 \quad$ [accessed 27 October 2016].

619

620 Roughgarden, J. 1976. Resource partitioning among competing species - A coevolutionary

621 approach. Theor. Popul. Biol. 9(3): 388-424. doi:10.1016/0040-5809(76)90054-X.

622

623 Salo, P., Nordström, M., Thomson, R.L., and Korpimäki, E. 2008. Risk induced by a native

624 top predator reduces alien mink movements. J. Anim. Ecol. 77(6): 1092-1098.

625 doi:10.1111/j.1365-2656.2008.01430.x.

626 
627 Schoener, T.W. 1974. Competition and the form of habitat shift. Theor. Popul. Biol. 6: 265-

628 307. doi:10.1016/0040-5809(74)90013-6.

630 Schoener, T.W. 1983. Field experiments on interspecific competition. Am. Nat. 122(2): 240-

631 285. Available from http://www.jstor.org/stable/2461233 [accessed 27 October 2016].

632

633 Schofield, P.F. 2003. Habitat selection of two gobies (Microgobius gulosus, Gobiosoma

634 robustum): influence of structural complexity, competitive interactions, and presence of a

635 predator. J. Exp. Mar. Biol. Ecol. 288(1): 125-137. Available from

636 http://dx.doi.org/10.1016/S0022-0981(03)00004-2 [accessed 27 October 2016].

637

638 Sih, A., Crowley, P., McPeek, M., Petranka ,J., and Strohmeier, K. 1985. Predation,

639 competition, and prey communities: a review of field experiments. Annu. Rev. Ecol. Syst. 16:

$640 \quad 269-311$.

641

642 van Beest, F.M., McLoughlin, P.D., Vander Wal, E., and Brook, R.K. 2014.

643 Density-dependent habitat selection and partitioning between two sympatric ungulates.

644 Oecologia, 175(4): 1155-1165. doi:10.1007/s00442-014-2978-7.

645

646 Wauters, L.A., Gurnell, J., Martinoli, A., and Tosi, G. 2002. Interspecific competition

647 between native Eurasian red squirrels and alien grey squirrels: does resource partitioning

648 occur? Behav. Ecol. Sociobiol. 52(4): 332-341. doi:10.1007/s00265-002-0516-9. 
650 Ziv, Y., and Kotler, B.P. 2003. Giving-up densities on foraging gerbils: the effect of

651 interspecific competition on patch use. Evol. Ecol. 17(4): 333-347.

652 doi:10.1023/A:1027385100393.

653

654 Ziv, Y., Abramsky, Z., Kotler, B.P., and Subach, A. 1993. Interference competition and

655 temporal and habitat partition in two gerbil species. Oikos, 66(2): 237-246.

656 doi:10.2307/3544810. 
657 Figure legends

658 Fig. 1 Schematic illustration of the experimental design showing 1) the different treatments 659 with sample sizes on the top and 2) division of habitat types and relative location of trapping 660 stations in each enclosure and control area below.

661

662 Fig. 2 The estimated (lines, mean \pm confidence interval) and observed (bars, mean \pm SE) 663 proportions of low cover habitat use by sibling voles (Microtus levis) and field voles (M. 664 agrestis) relative to vole densities in the absence (C-P-) and presence $(\mathrm{C}+\mathrm{P}-)$ of interspecific 665 competitors (C). P- refers to the absence of predators. Centred vole density refers to the 666 pooled (and centred) density of both vole species when under coexistence (C+), and 667 conspecific centred density when the species occurs alone (C-). The horizontal dotted line 668 represents short grass usages according to availability $(0.33)$.

669

670 Fig. 3 The estimated (lines, mean \pm confidence interval) and observed (bars, mean \pm SE) 671 proportions of low cover habitat use by sibling voles (Microtus levis) and field voles (M. 672 agrestis $)$ relative to vole densities in the absence $(\mathrm{C}+\mathrm{P}-)$ and presence $(\mathrm{C}+\mathrm{P}+)$ of avian and 673 mammalian predators $(\mathrm{P}) . \mathrm{C}+$ refers to all populations including both sibling voles and field 674 voles. Centred vole density refers to the pooled density of both vole species. The horizontal 675 dotted line represents short grass usages according to availability (0.33). 


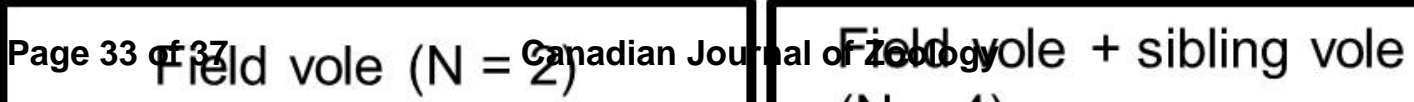

$(\mathrm{N}=4)$

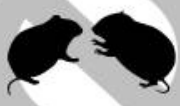

C-

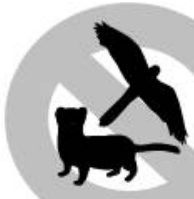

P_

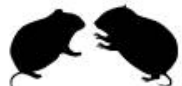

C+
Field vole + sibling vole

$(\mathrm{N}=3)$
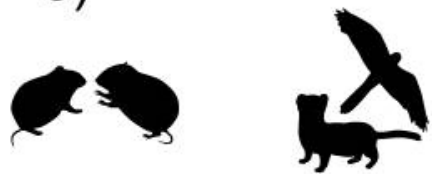

C+

$\mathrm{P}+$

Every 0.5 ha enclosure/control:

$\begin{array}{llllllll}\bullet & \bullet & \bullet & \bullet & \bullet & \bullet & \bullet & \bullet \\ \bullet & \bullet & \bullet & \bullet & \bullet & \bullet & \bullet & \bullet \\ \bullet & \bullet & \bullet & \bullet & \bullet & \bullet & \bullet & \bullet \\ \bullet & \bullet & \bullet & \bullet & \bullet & \bullet & \bullet & \bullet\end{array}$

Interspecific competition

Predation

-

-

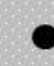

-
- $h$

-

https://mc06.manuscr

ptcentral. doowkjeovir habitat

High cover habitat

- Trap station 


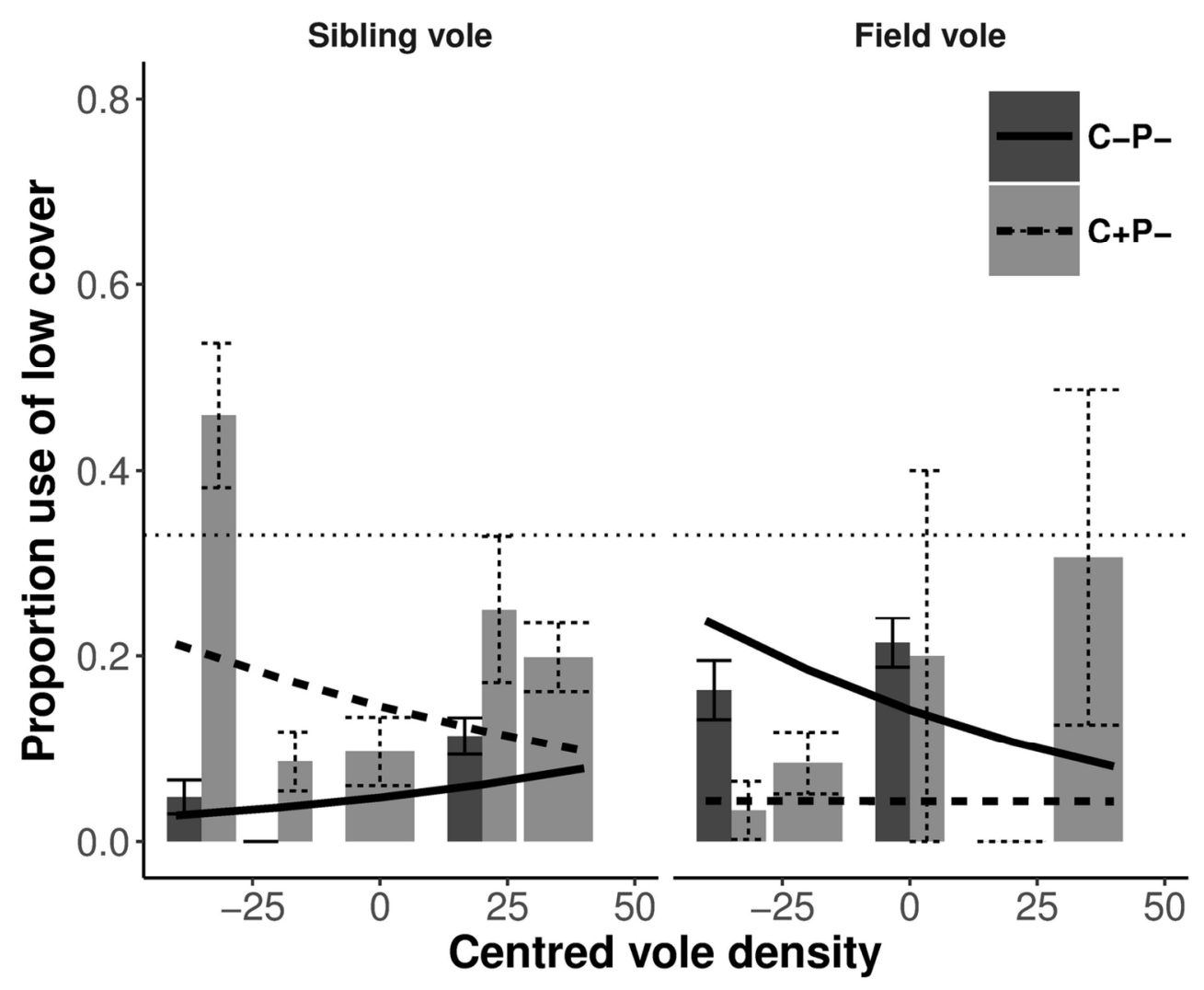

Fig. 2 The estimated (lines, mean \pm confidence interval) and observed (bars, mean \pm SE) proportions of low cover habitat use by sibling voles (Microtus levis) and field voles (M. agrestis) relative to vole densities in the absence ( $\mathrm{C}-\mathrm{P}-)$ and presence $(\mathrm{C}+\mathrm{P}-)$ of interspecific competitors $(\mathrm{C})$. $\mathrm{P}$ - refers to the absence of predators. Centred vole density refers to the pooled (and centred) density of both vole species when under coexistence $(\mathrm{C}+)$, and conspecific centred density when the species occurs alone (C-). The horizontal dotted line represents short grass usages according to availability $(0.33)$.

$127 \times 105 \mathrm{~mm}(300 \times 300$ DPI $)$ 


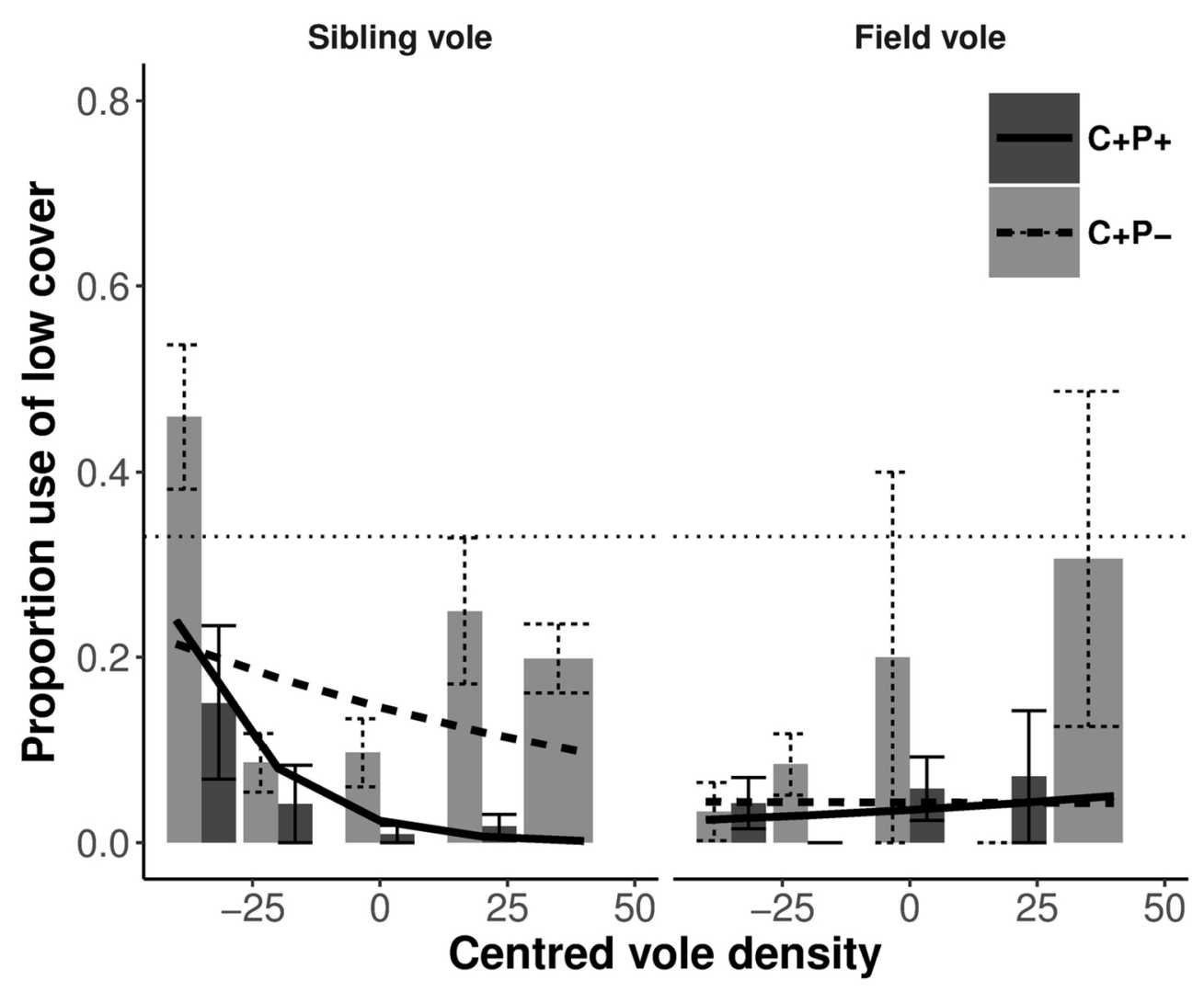

Fig. 3 The estimated (lines, mean \pm confidence interval) and observed (bars, mean \pm SE) proportions of low cover habitat use by sibling voles (Microtus levis) and field voles (M. agrestis) relative to vole densities

in the absence $(C+P-)$ and presence $(C+P+)$ of avian and mammalian predators $(P)$. $C+$ refers to all populations including both sibling voles and field voles. Centred vole density refers to the pooled density of both vole species. The horizontal dotted line represents short grass usages according to availability (0.33).

$127 \times 105 \mathrm{~mm}(300 \times 300 \mathrm{DPI})$ 


\section{Tables}

Table 1 Model output from generalized mixed models on the effect of competition (1068 captures of 837 voles from 8 populations) and predation (634 voles from 7 populations) on the proportional use of the low cover habitat. Data provided are effect estimates and their standard errors (Estimate and Std. Error), degrees of freedom (DF), $z$-values and $P$-values. Intercept represents the species sibling vole (Microtus levis) in the control treatment. Treatment refers to either competition or predation, depending on the model. Species_FV refers to field voles (M. agrestis). All significant effects are shown in italics.

\begin{tabular}{lccccc}
\hline & Estimate & St. Error & DF & z-value & P-value \\
\hline Competition model & & & & & \\
\hline Intercept & -3.004 & 0.362 & 1 & -8.303 & $P<0.001$ \\
Treatment & 1.238 & 0.439 & 1 & 2.819 & $P=0.005$ \\
Species_FV & 1.207 & 0.492 & 1 & 2.451 & $P=0.014$ \\
Centred density & 0.014 & 0.006 & 1 & 2.387 & $P=0.017$ \\
$\quad$ Treatment $\times$ Species_FV & -2.533 & 0.589 & 1 & -4.297 & $P<0.001$ \\
Treatment $\times$ cen.den & -0.025 & 0.006 & 1 & -3.895 & $P<0.001$ \\
$\quad$ Species_FV $\times$ cen.den & -0.029 & 0.008 & 1 & -3.833 & $P<0.001$ \\
$\quad$ Treatment $\times$ Species_FV $\times$ cen.den & 0.041 & 0.012 & 1 & 3.371 & $P<0.001$
\end{tabular}

\section{Predation model}

$\begin{array}{llllll}\text { Intercept } & -1.762 & 0.268 & 1 & -6.579 & P<0.001 \\ \text { Treatment } & -1.964 & 0.602 & 1 & -3.265 & P=0.001 \\ \text { Species_FV } & -1.333 & 0.324 & 1 & -4.113 & P<0.001 \\ \text { Centred density } & -0.012 & 0.003 & 1 & -3.484 & P<0.001\end{array}$




$\begin{array}{lccccc}\text { Treatment } \times \text { Species_FV } & 1.749 & 0.672 & 1 & 2.602 & P=0.009 \\ \text { Treatment } \times \text { cen.den } & -0.053 & 0.012 & 1 & -4.383 & P<0.001 \\ \text { Species_FV } \times \text { cen.den } & 0.011 & 0.009 & 1 & 1.204 & \mathrm{P}=0.229 \\ \text { Treatment } \times \text { Species_FV } \times \text { cen.den } & 0.062 & 0.021 & 1 & 2.948 & P=0.003 \\ & & & & & \\ \end{array}$

